Página inicial: 165 - Página final: 191

Tipo de artículo: de investigación

\title{
Significados en torno a la indemnización y la restitución en víctimas del conflicto armado en el municipio de San Carlos.
}

\author{
Meanings around the compensation and the restitution for victims of the armed conflict in the \\ municipality of San Carlos.
}

Recibido: mayo de 2015 Revisado: octubre de $2015 \quad$ Aceptado: noviembre 20 de 2015

Por: Juan David Villa Gómez ${ }^{1}$ y Alfonso Insuasty Rodriguez. ${ }^{2}$

\section{Resumen.}

Se resultados de las indagaciones sobre la valoración que las mismas víctimas del conflicto armado, del municipio de San Carlos Antioquia (Colombia), hacen de la implementación de la Ley 1448 (Ley de Victimas); dicho proceso de investigación, evidenció entre otros hallazgos, la contradicción entre el discurso oficial y el relato de las víctimas en relación a los procesos de reparación, discursos contradictorios respecto a la transición, el estado de vulneración e insatisfacción de necesidades básicas de las personas victimizadas así como una alta confusión en la implementación de la Ley. Estos resultados, entre otros, permiten afirmar que, la reparación hoy, dista mucho de ser un proceso que aporte a la reconstrucción del tejido social, a la paz y la reconciliación.

\section{Palabras clave.}

Reparación, Víctimas, Conflicto armado, Justicia Transicional, reparación integral, ayuda humanitaria

\begin{abstract}
.
The results of the inquiries on the valuation that the very victims make of the armed conflict, in the Municipality of San Carlos, Antioquia, Colombia of the implementation of the 1448 Law (Law of victims); such a process of research, made evident among other findings, the contradiction between the official discourse and the story of the victims in relation to the processes of repair, contradictory speeches regarding the transition, the state of infringement and dissatisfaction of victimized people's basic needs, as well as a high confusion in the implementation of the Law. These findings, among others, allow to affirm that, repair today, is very far from being a process that contributes to the reconstruction of the social fabric, to peace, and reconciliation.
\end{abstract}

\section{Key words.}

Repair; Victims; Armed conflict; Transitional justice; Full reparation; and Humanitarian aid.

\footnotetext{
${ }^{1}$ Psicólogo, Pontificia Universidad Javeriana (Bogotá - Colombia). Magister y PHD, Cooperación Internacional al Desarrollo Universidad Pontificia de Comillas (Madrid - España). Docente / Investigador Facultad de Psicología Universidad San Buenaventura (Medellín - Colombia). Contacto: juand.villa@usbmed.edu.co

${ }^{2}$ Abogado, Licenciado en filosofia, Especialista en ciencias politicas y políticas públicas, Estudiante de doctorado en el Instituto para el Pensamiento y la Cultura en América Latina (Ipecal-México), Docente Investigador Universidad de San buenaventura Medellín, integrante del grupo autónomo Kavilando. Medelín, Colombia. Contacto: Alfonso. insuasty@usbmed.edu.co
} 


\section{Introducción.}

El presente texto hace parte del proceso de investigación "Construcción de significados sobre la reparación institucional y la reparación desde abajo en víctimas del conflicto armado en el municipio de San Carlos", esta es la segunda entrega consecutiva, la cual se publicó en el volumen 15 número 2 (2015) de la Revista El Agora USB.

Estas dos entregas se realizan después de presentar un estado de la cuestión sobre el tema de reparación, publicados en los dos números anteriores de "El Ágora USB" (volumen 14 numero 2 y volumen 15 número 1), el equipo de investigación presenta en este texto algunos de los resultados obtenidos en el trabajo de campo, en el cual, se desarrolló un seguimiento significativo, desde la perspectiva de la población, a las acciones que el Estado Colombiano, en los diversos momentos entre 2008 - 2014, ha realizado en pro de la reparación de las víctimas en esta localidad.

El trabajo se desarrolló a través de una investigación cualitativa con el objetivo de recoger de viva voz la experiencia de los y las participantes.

"San Carlos es un municipio del oriente del departamento de Antioquia, quizás uno de los más azotados por el conflicto armado en el país en esta zona del país. Se calcula que cerca del 80\% de su población salió desplazada entre 1996 y 2003 (Centro de Memoria Histórica $\mathrm{CMH}, 2011$ ), quedando su perímetro habitado por entre 4.000 y 5.000 personas de las 25.500 registradas en el censo de 1993 (Olaya, Nunca más contra nadie. Ciclos de violencia en la historia de San Carlos, un pueblo devastado por la guerra. , 2012). Se habla de un desplazamiento forzado de cerca de 18.363 personas entre 1998 y 2006 (Centro de Memoria Histórica CMH, 2011) . Ahora bien, según la misma investigación (p. 373) la Acción Social en el año 2011 había registrado en el municipio la salida de 23.015 personas y la declaración como desplazados de 26.169.

Si bien el desplazamiento forzado emerge como la problemática y la afectación más visible en el municipio, es importante registrar que estos hechos estuvieron acompañados de cientos de graves violaciones a los derechos humanos e infracciones al derecho internacional humanitario en una guerra cuyo propósito parecía generar un escenario de terror para lograr un control absoluto del territorio. (Villa \& Insuasty Rodriguez, 2015)

\section{Metodología.}

Desde nuestro punto de vista pensamos que la valoración de este proceso tendría que hacerse desde la voz de las mismas víctimas, no desde la respuesta estructurada y delineada previamente por encuestas de satisfacción o instrumentos de medición que no logran recoger los significados y experiencias de la gente y que se plantean desde un marco institucional delimitando un marco de respuestas posibles, que generalmente dan poca cabida a la expresión de los sentidos, significados y experiencias vividas por la gente como destinataria de programas y acciones estatales con fines de reparación. Por eso, hemos optado por un método cualitativo, apelando a diversas estrategias metodológicas para triangular información: 12 grupos focales (GF), con la participación de 150 personas, 
7 entrevistas individuales (EI) y 5 entrevistas grupales (EG) para completar un número de 170 personas participantes. (Villa \& Insuasty Rodriguez, 2015)

\section{Resultados.}

\section{Significados sobre la indemnización.}

Aun cuando las instituciones del Estado afirmen estar haciendo todo para evitar esta confusión entre ayuda humanitaria, política social y reparación, en el imaginario de la gente sigue siendo muy fuerte. Es importante aclarar que este componente de la reparación "busca reparar a las víctimas por los daños materiales, fisicos, mentales, a la reputación y a la dignidad sufridos, los gastos incurridos, las pérdidas de ingreso y de oportunidades, y los costos de asistencia jurídica y servicios médicos, entre otros, cuando no sea posible la restitución a la situación anterior o cuando las víctimas no la deseen" (Centro Internacional para la Justicia Transicional y Centro de Estudios de Derecho, Justicia y Sociedad , 2009, pág. 40):

Esta es como la comprensión que hemos venido ganando y es, aqui están los hechos victimizantes asociados al conflicto desde la ley 1448 del 2011 y esos hechos victimizantes están en razón de actores armados y también de comunidades que asumen hechos desde nominarse desde uno u otro grupo, actores legales e ilegales, nombrémoslo así para que quede más claro y entonces preguntábamos: bueno, estamos en un momento en el que el Estado supuestamente, supuestamente no, está haciendo como una acción de contención a estos hechos victimizantes, pero la contención no es contención, es contener pagando y es contener con acciones que no están pensando el fenómeno... (EI3)

Ahora bien, la clave del proceso de reparación no está en lo que se haga: si se da una indemnización o se construye un monumento o se hace alguna restitución; la clave está en la forma: que la indemnización no sea una compra ni una transacción, que los monumentos no sean una forma de pasar la página rápido. Siempre, y en todo momento, la clave está en el reconocimiento público, social y moral que se haga de las víctimas (Hamber, 2000; Martín Beristain, 2008, 2010a, 2010b; Villa, 2013; Villa, Londoño \& Barrera, 2015). Cuando la reparación termina por centrarse única y exclusivamente en lo material, ocasiona efectos perniciosos en la población que la recibe, entre estos es posible señalar la disminución de la autoestima, de la confianza y de la esperanza y la aparición o el incremento de sentimientos de culpa que conduce a que se perciba el dinero recibido como una humillación o "dinero fácil", lo que exacerba los daños e impactos generados por los hechos victimizantes y no dignifica. En el contexto colombiano estas afirmaciones adquieren materialidad, puesto que muchas personas víctimas significan la reparación como una caridad que no repara y se perciben a sí mismos como receptores de una "ayuda" del Estado sin lograr, antes de ésta o a través de ésta, reconocerse como sujetos de derechos, cuyo cumplimiento es un deber del Estado (Villa, 2013, 2014b; Villa, Londoño \& Barrera, 2015):

¿Qué está pasando con todas esas indemnizaciones que se están entregando aquí en el municipio? Muchas cosas. Esas entregas masivas de las cartas de dignificación y las carta-cheques, son entregas como sin verdaderamente atender el uno a uno, sería muy costoso atender el uno a uno, pero es una carta igual para todos y una intervención como "bueno, acá está" el papá Estado dice "reconozco que no cumplí con el pacto 
constitucional que teníamos como ciudadanos y hago una reparación simbólica y pues da estos millones" y todos salen con su carta cheque de la jornada; pero bueno, antes de salir hay unas acciones de los funcionarios invitándolos a entender qué significa eso, como tratar de invertirlo de una forma que esté asociada a daño, comentan que en muchos casos las familias compran motos y después el hijo muere en un accidente o se lo beben y parrandean, pero hay como una feria rotativa en opciones de emprendimiento agrario, priorización de algunos cultivos, ofertas institucionales. Pero a mí me parece que pasa una cosa ahí importante a ver, la jornada es valiosa, se hace, yo creo que es importante entender que el hecho de hacerla debe estar unida con unos sentidos de cómo hacer eso, pero buscando que no sea simplemente entregar millones para muchas familias que han tenido muchos años de penurias económicas, de un momento a otro una familia que ha estado viviendo con ayudas humanitarias, con trabajos muy dificiles por días, por horas y llega una indemnización de ese valor. Ahí es importante el proceso de acompañamiento en las entregas que se hagan previamente, creo que hay un proceso que se puede hacer ahí y que continuara también; porque la jornada como yo la entiendo es que la gente espera largamente para que se le haga la entrega, llega el día, participa en una actividad de dos o tres horas y después los convocaran a algunas actividades pero muy desarticuladamente diría yo. Entonces una acción que pretendía ser reparadora posiblemente es una acción potencial de daño. Para mí ese potencial de daño está representado en que para muchas familias no hay un proyecto claro de cómo ese dinero se articula con sus proyectos de vida y ese dinero es "me pagan un muerto o me pagan un daño que he recibido y lo invierto en ciertos elementos que considero que son necesarios"; pero no corresponde digamos como a proyectos, algunos proyectos sí los hacen pero en términos de lo masivo se queda una gran parte de la población sancarlitana sin acompañamientos psicosociales o acompañamientos más específicos en lo que tendría que ver con eso (EI3).

Este contraste muestra las dificultades en los enfoques y en las miradas. Es comprensible que el Estado tenga una prioridad en evacuar en el mínimo tiempo, con el mínimo de gasto y con una maximización de la acción en términos de tiempo, recursos humanos y número de personas atendidas. El tamaño del problema a nivel nacional y en el municipio es tal, que la urgencia de la acción, termina subsumiendo aspectos fundamentales que se deben tener en cuenta para que esta acción sea realmente reparadora, al punto que en vez de mitigar los efectos iatrogénicos, los puede exacerbar. Aun así, y a pesar de los esfuerzos enunciados, la sensación y las significaciones en la población que participó en esta investigación deja muchas más preguntas que respuestas:

...de otro lado hay mucha gente que se siente afectada, dolida en que la intervención muchas veces no pase de ser un cheque o una plata y que las otras medidas de pronto estén tan pobremente acompañadas... Porque la única medida que el estado medianamente ha empezado a implementar es indemnización, un poco la rehabilitación fisica... las medidas de satisfacción se han hecho algunas cositas, bueno no, algunas cositas en el tema simbólico, porque sabemos que en el tema de la verdad estamos en cero o en un porcentaje muy escaso y en ese tema de la verdad impacta directamente, las garantias de no repetición, donde también estamos cero. Entonces muchas veces ¿qué puede pasar? que el Estado solamente ha mostrado la indemnización, entonces por eso la gente piensa que esa es la única o a unos solamente les interesa esa... (EI2) 
Una de las principales consideraciones generada en los grupos focales y en algunas de las entrevistas, que se extendió de forma general es que la indemnización que se entrega no es suficiente frente al daño que se vivió, el tamaño del daño es tal, que el dinero entregado no compensa lo perdido, ni en términos materiales, ni simbólicos ni afectivos, tal como se anotó anteriormente es del todo insuficiente para compensar el daño y todo lo perdido. Es un intento de compensación, pero no logra serlo, tal como se enuncia desde las instituciones. Además de lo anterior, debería estar acompañada con acciones integrales que posibiliten la reconstrucción del tejido social y el proyecto de vida de las personas; sin embargo, como el número de personas participantes en los proyectos es bajo, en comparación con la cantidad de víctimas, la medida de la indemnización, como se ha dicho, termina siendo la más visible; y para muchos, la única. Por tanto se percibe como insuficiente:

La indemnización que les dan a las víctimas se está dando pero no alcanzan, es que uno después de todo eso que vivió no quiere sino estar estable porque hemos estado de aquí para allá, eso no es justo nosotros no pedimos que se hiciera eso, que nos mataran la familia y menos salir de aqui, es que cuando uno es pobre y no tiene como, pues no hay de otra. Pero esas indemnizaciones no sirven yo veo que no funcionan, la gente se las gasta o ni siquiera le llegan... (GF2). La indemnización deberá ser una ayuda buena, porque a muchos nos ha estabilizado un poco aunque no es la solución y con eso no me pagan el dolor que sufri al perder a mi hermano (GF2)

Por ello para algunos y algunas, al igual que la ayuda humanitaria, se tiene claro que no se está pidiendo limosna, y que su insuficiencia, en algunas ocasiones se convierte en una intervención que puede generar indignación y no conformidad de parte de las víctimas:

Para mí la indemnización no es nada, para mi esa indemnización no es nada; me quedan 4 millones de pesos a mi aproximadamente; iNo! Es que yo no soy un limosnero, voy para 59 años y me siento capaz de moverme, yo no necesito que me den limosna, si necesitara que me dieran limosna cojo y me quito la gorra y me voy para la calle a pedir, para mí eso es una limosna (EG1).

Además porque la pérdida no fue solamente material, se pierden proyectos de vida, se pierden espacios vitales, incluso, como lo afirman en el siguiente grupo focal, se pierde toda una etapa de la vida, se perdió una generación:

Hablando de ese tema de generaciones, a San Carlos lo deberian reparar por generaciones, de tal edad a tal edad, diferenciar. Adultos, jóvenes, niños. Toda la población de San Carlos perdimos una generación. Yo por ejemplo perdi casi una década, de 14 a 28 años, nos tocaba vivir encerrados, no podia hacer uno lo que hacen los niños de ahora, entonces ahi es donde uno coloca como el nivel, ¿si será que le reparan a uno con 2 millones de pesos? Es que se perdió una generación por la guerra. La juventud mía la perdi encerrado corriéndole a eso. Otros perdieron la niñez y quizás más graves. A nosotros nos fue bien, muchos como perro en misa (GF5).

A su vez, se considera que esta medida no toma en cuenta ni lo perdido, ni los años cesantes, ni las pérdidas simbólicas, ni las sociales. Pero en términos exclusivamente económicos no logra compensar lo que se perdió, lo que se había construido en un proyecto 
de vida con el trabajo personal y familiar. Por tanto, la significación puntúa en lo faltante y no en lo que se ha logrado con la indemnización,

...entonces a nosotros de que nos sirven si nos dan 8 o 10 millones de pesos como reparación, y que ya no somos personas desplazadas, que ya con eso perdemos el código, que ya con eso perdemos los derechos, entonces tenemos que rehacer la vida como si no fuéramos desplazados y entonces ¿A dónde se quedan los años cesantes, a dónde se queda lo que se llevó la guerrilla o la delincuencia y a dónde se nos queda el daño material y psicológico que nos han causado? O sea ¿con 8 o 10 millones, van a que nos van a reparar absolutamente todo? (GF6)

En este sentido hay una diferenciación que se hace evidente a lo largo de la investigación, y es que las personas en situación de desplazamiento que no tuvieron que padecer otros tipos de victimización centran sus reclamos, y con toda razón, en la dimensión económica y en la restitución de lo perdido. Entre otras cosas porque las condiciones sociales y económicas a las que se vieron avocados fueron de una total vulnerabilidad. De alli que la indemnización considerada en la ley 1448 y en sus decretos reglamentarios, de 17 salarios mínimos, sea considerada más que insuficiente. Entre otras cosas, porque la gran mayoría de los retornantes no han tenido la posibilidad de ser "beneficiarios de los proyectos estatales que han promovido y respaldado el retorno (Alianza Medellin- San Carlos, Familias en su Tierra fases 1, 2 y 3; Convenio 15-10, entre otros).

De otro lado para los familiares de las personas asesinadas y/o desaparecidas, es claro que la vida no tiene precio, y que el dinero no compra el dolor y el sufrimiento que se ha vivido, ni es capaz de "compensar" esa pérdida:

Es un pequeño alivio porque una vida no tiene precio, si a mi me dicen: le doy 100 millones por la desaparición de mi hijo, no tiene precio. 15, 16 millones de indemnización y personas que se van con 2 millones y firman que están reparadas... (GF3). Yo digo algo: por más plata que uno reciba, por más ayuda psicológica que uno reciba, nosotros no estamos totalmente sanos y la plata no nos va a cubrir esa persona que se fue o ese dolor que sentimos... Por más que den, por más que hagan, uno nunca sana eso... el dolor queda allí (GF7).

Por esta razón algunas personas manifiestan que en este tipo de acciones puede haber un intento de comprar el dolor, una "ayuda"; que, al parecer, no genera los efectos compensatorios que las víctimas necesitan para transformar su condición de vida, sino que por el contrario terminan siendo paliativos con los que la gente ni experimenta reparación ni siente que se transforme su condición actual ni su subjetividad (Villa, 2013).

Lo que pasa es que el gobierno cree que dándole a uno un dinero con eso restituyen el dolor (GF4). ...otros piensan que ese dinero está pagando culpas y dicen no, esta plata no sé si sea maldita, pero sí es una plata que antes que edificar daña, es muy complejo los sentidos también de eso (EI3).

De acuerdo con Sikkink, et. al. (2014) al realizar el estudio comparativo con otras experiencias que podrian tener semejanzas con el caso colombiano, este tema es particularmente sensible en algunos contextos como el de Guatemala, donde algunas comunidades y 
personas identificaron este tipo de reparaciones como acciones que generaban daño a la gente: "las victimas de la comunidad de Q'eqchi, por ejemplo, han destacado la capacidad que tiene la compensación colectiva para promover la cohesión social y expresado su molestia con la compensación individual. "Es como si...ellos estuvieran solamente pagando por los muertos", señaló uno de estos beneficiarios. "Es como el caso de mi madre. Ellos me van a pagar por ella; yo me voy a comer a mi madre". Los encuestados también indicaron una fuerte preferencia por la restitución de los bienes perdidos durante el conflicto, particularmente las viviendas. Para ellos, la compensación individualizada que estaban recibiendo del Estado era más una forma de "ayuda" que una reparación por su sufrimiento" (Sikkink, et. al., 2014, p.43). Estas afirmaciones son confirmadas por las investigaciones de Mack (2007) y Viaene (2008) que evidencian la insuficiencia de las medidas de indemnización, mucho más en contextos de pobreza estructural y vulnerabilidad de la población.

La pregunta que surge es: ¿estas "indemnizaciones" tal como se han venido dando, son en efecto reparadoras? ¿Por qué, según lo afirmado por las víctimas en esta y otras investigaciones sobre el tema (Cfr. Villa, 2013), el Estado piensa que con dar un dinero estaba cumpliendo con su papel como garante de la reparación? ¿Cuál es la intencionalidad que podria rastrearse allí Los testimonios y relatos de los y las participantes que buscan esta reparación, de los que no la han recibido y de quienes la recibieron permiten evidenciar un imaginario que puede derivar en la cosificación de las personas, limitándose a una transacción en la que el Estado proporciona esa "ayuda", pero como no se confia en una acción reparadora, se entra en la lógica de "negociar" montos o reclamar un precio:

...entonces uno a veces hasta dice, tan teso, también como van cosificando y como van diciendo es que mi hijo no vale 20 sino que vale 30 y personas, porque es que yo tengo el otro lado, personas que recibieron indemnización ya una vez y digamos que recibieron indemnización hace 10 años cuando la red de solidaridad le entregaba 10 millones, porque en su momento a esos equivalian los salarios minimos, ahora vienen a pedir como dicen ellos la liquidación o el reajuste, que a que le den la otra parte que les corresponde o que vienen por la otra indemnización, entonces eso hace parte del mismo modelo de intervención de como el signo pesos, se ha quedado en muchas personas... (EI2)

En una investigación anterior, Villa (2013) afirmaba que en un contexto de dominación y explotación de las víctimas por parte de los victimarios y sus cómplices, en un contexto de impunidad, como el que aún se sigue manteniendo en buena parte del territorio nacional, las reparaciones, sobre todo cuanto tienen un tinte centrado en lo material, pueden traer consecuencias negativas para las mismas víctimas, como pérdida de la autoestima, de la confianza y de la esperanza, (Yzerbit \& Demoulin, 2010), beneficiando al grupo dominador (Barkan, 2000), alterando, en algunos casos, los procesos de recuperación emocional; pero además generando una desesperanza aprendida y una lógica de relación con lo público centrada en la recepción de favores, un marco de paternalismo y asistencialismo que no posibilitan una auténtica reparación.

Ahora bien, los y las participantes en esta investigación se ubican en una dinámica pragmática que parte de un análisis simple. El Estado ha generado mecanismos legales para reclamar un dinero con el que no se contaba, en un contexto donde no se tiene confianza en el Estado y las relaciones con el mismo y el acceso a los servicios sociales están mediados 
por relaciones clientelares (González, Bolivar \& Váquez, 2002; Villa, 2013, 2014 a; Villa, Londoño \& Barrera, 2014). En este contexto, la gente prefiere hacer la gestión, reclamar el dinero, resolver necesidades básicas, puesto que la mayoría viven en condiciones de pobreza extrema, y asumir lo que la ley dice; puesto que suponen que si no "toman" este dinero, quedará regado en las redes de corrupción del país, se quedará en otras manos y se "perderá". Así pues, se acepta la transacción, porque no se espera tampoco más. Esta mirada pragmática lleva a la gente a realizar tres tipos de razonamiento.

El primero tiene que ver con la puja por el monto que deben recibir, según las tablas que se han determinado en la reglamentación de la ley, de acuerdo con los tipos de victimización

Lo que a uno le parece loco es que supuestamente es por desplazamiento, pero hay gente que tuvo también víctimas, lo que dice el gobierno nacional o según la ley, es que una persona no puede ser beneficiada por más de 22 millones de pesos, independientemente de que hubiera sido indemnización por desplazamiento (GF11).

Hubo gente que declaró y le vino más buena plata a los que lo hicieron del 2008 hacia atrás, de ahí en adelante hay un castigo de 5 millones más o menos por no haber declarado, y es por eso, nadie hablaba, ¿por qué?, ¿cómo? Lo que pasa es que la ley de victimas los que habian declarado desde marzo, abril del 2008 hacia atrás, les llegaban 27 salarios mínimos legales y los del 2008 hacia acá, les llegaban 17 salarios, mucha gente declaró desde el 2005, 06, 07 (GF12).

Como se ha esbozado, esta forma de comprender la reparación, y sobre todo, un énfasis mayor en la medida de indemnización, conducen a este tipo de discusión. Aun así, según la magnitud del daño y según lo vivido, seguirá, en todos los casos experimentándose como insuficiente, "...lo que se perdió fue demasiado, con las indemnizaciones uno arregla unas cositas... Eso es lo mismo que usted invitarlo a una reunión en Rionegro, "vengan a una reunión de a pie y lo ayudamos con el pasaje”... (GF6)

En esta misma lógica se plantea el segundo tipo de disquisición. Existe un reproche generalizado a la forma como se está distribuyendo el monto de la indemnización. De acuerdo con el parentesco y al número de familiares, se ha establecido también una cantidad en una distribución del monto tazado entre los familiares de la víctima, o entre los miembros de la familia que sufrió el desplazamiento (en el caso de este hecho victimizante). Esta disposición ha ocasionado enormes dificultades, puesto que la percepción con la que quedan las personas es que, si el monto total era insuficiente para reparar lo perdido (en el caso de los desplazados) o para compensar el daño o la pérdida del familiar (en los otros casos), lo será mucho menos con esta distribución individualizada del monto de la indemnización,

Hay otro tema en reparación económica, porque es inequitativa, no es lo mismo 15, 18 millones por núcleo familiar, porque si somos 2, bueno, pero donde son 5, 6, 7, 8 personas eso no alcanza ni a sueldo mínimo mensual, entonces esa ¿es la reparación económica?, de que le sirve eso a una persona, hay que pensar equidad en términos de núcleos familiares numerosos, amerita pensar eso, porque tendriamos que hablar de un concepto de reparación económica individual, pero son inquietudes que quiero dejar... (GF3) 
Esto se considera inequitativo y poco reparador. Mucho más cuando en algunos discursos se plantea que un objetivo de estas "indemnizaciones transformadoras" es generar procesos de superación de la situación de vulnerabilidad en la que han caído las personas y las familias que han sido víctimas del conflicto armado que, cabe aclarar, más que vulnerables, deben definirse como vulneradas, puesto que su situación no responde a una situación estructural de pobreza, sino a un empobrecimiento y vulneración de sus derechos,

...cuando llega una cartica con una indemnización, dios mio ¿qué es una indemnización para mí que somos 5 personas y que a mí me lleguen 2 millones de pesos? Vale más la papelería. Yo no estoy diciendo aqui que el Estado no esté haciendo nada, el gobierno nacional se ha esforzado y ha hecho hasta lo imposible para que San Carlos salga adelante, pero yo se lo dije propiamente al director que vino acá para cuestiones de la indemnización, vea Señor, con todo el respeto que usted se merece y trabaje por allá en lo más alto donde sea, está en este momentos en San Carlos, que me entrega usted a esa carta le firmo por detrás y le digo lo que tengo que enviarles a ustedes por escrito porque ustedes no lo escuchan a uno... (EG2)

Además de lo anterior para algunos participantes se hace muy dificil aceptar que los dineros que corresponderian a los menores de edad en esta distribución, no sean entregados a la familia, ni a los padres, sino que son guardados en una fiducia, a manera de un ahorro, para que sean reclamados cuando cumplan su mayoría de edad. Si bien, esta disposición tiene la intención de proteger la compensación que le correspondería al menor de edad, para algunas familias numerosas, que luego del desplazamiento perdieron todos sus bienes, puede llegar a ser no una experiencia reparadora, sino nuevamente una "ayuda" que no permite la reconstrucción de sus proyectos de vida,

...se les está dando una indemnización de casi 16 millones de pesos, con lo que no estoy de acuerdo es con que... yo tengo en mi vereda una familia que es de 10 persona, papá, mamá y 8 hijos. Si les dan los 16 millones, a cada uno le dan una partecita, les llegan la plata de papá y la mamá, a los hijos hasta que no cumplan los 18 no se las entregan, que van a hacer ellos con 2 millones 600 mil pesos, que es lo que les entregarian, los del papá y la mamá, porque la otra plata la entregan cuando los pelaos cumplan 18, ¿qué reparación hay ahî? ¡Ninguna!, ahí no hay ninguna reparación... (GF6)

Mucho más cuando no hay confianza suficiente en el sistema financiero, teniendo en cuenta que serán años los que tengan que pasar antes que algunos menores puedan acceder a este dinero, con lo cual, y de manera realista, la gente plantea que con la devaluación y la inflación, el valor real será muchísimo inferior cuando sus hijos puedan disponer de ello, llegando incluso a plantear el dilema en términos de lo justo o lo injusto. La pregunta sería la siguiente: ¿Es justo que ante un daño que se taza en términos monetarios y que se pretende reparar, cuando se pueda reclamar, el monto real de ese daño haya perdido su valor?

...hay dineros que están en los bancos para niños que deben esperar hasta que crezca. Pero no es justo. Hay una incredulidad con los bancos, ya han pasado casos de que se pierden los dineros... quién nos garantiza que el dinero va a estar siempre allá en el banco y que no se va a perder para cuando mi hija cumpla 18 (GF2). ...la indemnización son 15 millones, por ejemplo así, en el caso mío, yo hice esa vuelta pero a mí eso no me ha 
llegado, por ejemplo, yo tengo, todos mis hijos son menores de edad, el esposo mío falleció, y yo, soy la que trabaja y le doy estudio pues a todos, pero como son menores, solamente llegaria la parte que a mi me corresponde, como dos millones y bolita, yo le pregunto, tengo una niña, la última tiene como 3 años, yo le pregunto: cuando esa niña tenga 18 años, vendrian a entregar la parte que a ella le corresponde, a nosotros no, ¿usted cree que eso es justo?, eso no es justo (GF11).

La pregunta por la justicia de esta medida la plantea con mayor radicalidad una participante que ha estado cerca de varios de los proyectos ejecutados en el municipio, participando en caracterizaciones de la población y en procesos de valoración de la situación actual de la población quien manifestó lo siguiente:

Otro problema que tenemos cuando fueron a las indemnizaciones y lo de la fiducia, bueno ellos se tomaron la tarea de consultarle a la gente, de hacer no sé, un censo, o algo de consultarle a la gente, ¿ustedes están de acuerdo de que el dinero de los menores quede en una fiducia? Cuando hay gente, acá en San Carlos hay hambruna y lo digo porque yo he sido parte de las que yo me he recorrido todas las veredas de San Carlos y acá en San Carlos hay hambruna, acá la gente aguanta hambre, acá hay ancianos, gente de la tercera edad, levantando y criando bisnietos, por culpa del conflicto, donde tienen una agua panela o ni una agua panela (EG2)

Esta situación de acuerdo con algunos y algunas participantes ha traído consigo un daño en el tejido familiar, ha servido para generar distancias y rupturas en las relaciones familiares; no ha permitido la reparación de vínculos y por el contrario ha generado malestares que han distanciado a miembros de algunas familias. Puesto que desde el contexto del municipio, algunos daños tienen una connotación claramente familiar; y una lógica demasiado individualizante en la lectura del daño y la posterior reparación no contribuyen al fortalecimiento de los vínculos familiares en un contexto donde también, éstos, se han visto afectados por el conflicto armado,

...le diligenciábamos el PAARI y venia la x y decía es que él es un... y uno se daba cuenta de todo el conflicto familiar, y que se desató a raíz de esa indemnización, es que no me incluyó y yo soy la esposa y yo la moza y yo la amante, o sea cantidad de cosas que en vez de unificar, y lo que para mí se hizo fue desarticular más la familia, porque ya las, porque ya las peleas de que le va a llegar a aquel y no a mí no me va a llegar, a mí me tocaba tanto, no no no no y eso venían con cerros de papelerias, es que vea yo soy esta, yo soy este, pues da tristeza, eso a mi me da mucha tristeza (EG2).

Esta lógica de cargar buena parte de la reparación en los procesos de indemnización a las víctimas, centradas en la ayuda en primer lugar, y luego en medida de compensación, y al poner énfasis en una estrategia centrada en una dimensión económica, también genera una paradoja en relación con esa ayuda y esa indemnización: la gente que pedía ayuda humanitaria, intentaba registrar más familiares para obtener más ayuda; pero a la hora de la indemnización ya no quieren incluirles, porque se disminuyen los montos, como se evidencia en este relato: 
En cuanto a la parte del dinero, hay muchas personas que lo reciben de muy buena manera, que dicen "no, ¿qué más nos van a ayudar?, esto nos va a servir" y que le han dado muy buen manejo a los recursos, hay otras personas que no lo han hecho. Lo que uno ve es que las familias si están muy decaidas y como anteriormente para todo el resto de programas, entre más número de familiares hubiera las familias recibian más dinero, que fue el caso de las ayudas humanitarias, entonces si yo tenía doce en mi núcleo familia, la paga era mucho; pero resulta que se les fue el tiro por la culata, como nosotros decimos normalmente, porque "a los doce no le vamos a dar esto, esto, eso, sino son 15 millones se dividen en los doce". Entonces la gente ya era desesperada, "es que este no es de mi núcleo familiar, es que este no se quien lo metió ahi”. Entonces al momento de hacer eso, ese fue como uno de los problemas que hubo (EG3)

Esta paradoja no nos habla sólo de las lógicas de la población, ni solamente de las lógicas del Estado; nos evidencia el tipo de relación que se ha establecido con la población en un horizonte donde se ha priorizado un estilo y una forma de acción, sobre otras posibilidades, donde ha primado el cumplimiento de la meta y el número, sobre los procesos; donde las instituciones que ejecutan las acciones vienen de fuera y no logran construir con la gente y desde abajo dinámicas reparadoras; donde finalmente se establece una relación asistencial, que no permite una real reconstrucción de tejido social y proyectos de vida, y donde quien dice reparar, aun haciendo sus mejores esfuerzos, termina quedando en deuda con los "sujetos" de esa reparación: “...porque hay gente que en su vida no ha llegado a recibir 2 millones de pesos así junticos y los coge y no sabe qué hacer con eso, entonces en parte esos programas por ser manejados desde el escritorio han generado parte de la problemática...” (GF6).

De esta manera la insatisfacción se da en ambos lados: las personas que laboran en las instituciones porque piensan que sus esfuerzos y acciones no están siendo reconocidos por la población, pero que no logran ver que la forma como han estructurado la relación con la población implica verticalidad, paternalismo y ponerse en el marco de una relación "caritativa", lo que en el contexto de violaciones de derechos y ejercicio de la reparación integral, los deja siempre en deuda; pero a su vez, las víctimas porque al acomodarse a esta transacción y a este marco sistémico de relación, renuncian a su posibilidad de actuar como sujetos políticos, asumiendo el rol de "receptores" de ayuda, lo cual les pone en permanente falta, en permanente demanda, ocupando un lugar que no quieren ocupar: el de "limosneros", beneficiarios de una "caridad institucional": "...pero es que mucha gente las enseñaron a ser buen mendigo, entonces es muy duro para un municipio sostener una población tan grande y que a toda hora es deme y deme y no, yo creo que hay que darles el anzuelo para pescar pero que ellos saquen el pescadito" (EG3).

El tercer tipo de razonamiento y disquisición tiene que ver con la búsqueda de posibilidades para invertir el dinero, para intentar solucionar necesidades apremiantes de vivienda, salud, educación, e incluso alimentación o trabajo, lo que ha implicado que una buena parte de los dineros recibidos se hayan invertido en la solución de necesidades básicas que no pueden posponerse, lo que refuerza el sentido que se le da, como ayuda económica, más que como compensación del daño: 
De lo del tema de la indemnización, la gente aqui espera la ayuda y la ayuda no es mucha, porque como lo han dicho no es mucha, pero para muchos ese poquito de ayuda que les llega les sirve muchísimo porque como dice la compañera hay muchas falencias, hay mucha escases digamos de todo, entonces para ellos esa ayuda es, como le digo yo no sé, la esperan tanto que cuando llega ya la tienen toda repartida. Ya está gastada. La gente se mete en tantas deudas y tantas cosas que cuando llega ya... De lo que yo les decía de la hambruna se lo digo porque yo estuve como encuestadora en la actualización de bases de datos de la administración, entonces donde yo veía, estas personas tienen la custodia de los nietos o bisnietos y es gente que estaban esperando un poco para satisfacer un poco las necesidades que tienen, hay gente que recibe y lo primero que va y hace es hacerse un mercado como nunca jamás, quien sabe en cuantos años se lo habian hecho (EG2).

A pesar que éste ha sido uno de los puntos donde se ha centrado la acción de la UARIV, tal como lo devela en su informe, y de otras instituciones locales para evitar que la gente malgaste su dinero, las realidades de la vida de las familia, en algunos casos son tan apremiantes, que aún con la información financiera recibida y con los procesos educativos en estos temas, la situación económica real de muchos y muchas desborda estas posibilidades de inversión hacia el futuro o dirigidas a superar condiciones de vulnerabilidad, puesto que el recurso se utiliza para subsanar la vulnerabilidad y el empobrecimiento acumulado de años en una situación de desprotección y abandono de ese mismo Estado:

Cuando nosotros íbamos con el tema de las indemnizaciones estuvimos dando unas capacitaciones en todo el municipio en educación financiera, no nos vamos a endeudar todavía, porque no tenemos la platica, no sabemos qué va a pasar, para cuando nos va a llegar, a pesar de que se lanzaban unas fechas, que en este tiempo, en esta fecha, que para mi siempre ha sido como imprudente manejar fechas en cuanto a una cosa que es como tan incierta, era la educación financiera y le haciamos énfasis en vea no se endeuden y ver ahora a la gente pagando deudas, estoy pagando intereses altos de esto y les digo yo pero venga de que les sirvió entonces estar en esa capacitación, de que les sirvió si les deciamos no se endeuden, no hagan eso, no saquen materiales fiaos, que no se sabe que pueda pasar, porque ya se veía en otros proyectos que las ayudas y los incentivos, para tal fecha no llegaban, para tal fecha no se pudo, ¿'entonces para cuándo? (EG2)

Así pues, el problema es que buena parte de este proceso se ha centrado en ofrecer información y posibilidades de inversión, sin poder partir de la experiencia de vida de la gente, sus necesidades, sus realidades económicas, su empobrecimiento a causa de la guerra. Se parte de concepciones previas sobre lo bueno y lo deseable en torno al dinero que se entrega y no se tiene una mirada contextual, social, cultural de lo que significa para esta gente este dinero, de las experiencias de exclusión y humillación económica por las que han pasado, de la escasez experimentada luego de períodos anteriores de mejores condiciones de vida. Así pues, esta acción educativa sigue siendo descontextualizada y no logra mitigar el daño potencial que puede generar.

A esto se le añade la espera, puesto que lo que es importante para estas personas víctimas no es la promesa de reparación, sino la materialización de dicha promesa, ya que es fundamental que exista un balance entre la las promesas que se le realizan y la capacidad institucional y la disponibilidad de recursos para cumplirlas (González Chaverra, 2010). Al 
respecto, Jaramillo (2012) advierte que en las comunidades en Colombia hay una espera incesante por algo cuyo valor y forma son especulados cotidianamente, lo que ha también ha generado actitudes de sumisión en las víctimas frente al Estado, que ha cristalizado en relaciones de dependencia (Villa, Londoño \& Barrera, 2014), puesto que "la espera también implica un proceso donde los sujetos de la verdad y de la reparación entran en un estado de desesperación en un doble sentido. Por un lado, se ubican en la inevitabilidad de una perpetua espera. Las personas aprenden que el estado subjetivo de la demanda por derechos es algo asociado a la incertidumbre por el futuro y el ritmo azaroso (...) En otras palabras, una deuda inicial de reparación habia sido convertida, a través de la desesperación, en una promesa de lealtad de las víctimas hacia el Estado " (Jaramillo, 2012, pág.56-57).

Pero además, tampoco se logra compensar lo perdido, ni en términos materiales ni sociales, ni afectivos. Con lo cual, este dinero termina siendo sencillamente un paliativo más, dentro de una cadena de acciones estatales que se sitúan más en el plano de la asistencia que de la reconstrucción. De una u otra forma una reparación centrada en lo económico, tal como la percibe la gente en esta investigación y en otras anteriores (Cfr. Villa, 2013) no toma en cuenta las complejidades del contexto, con las consecuentes experiencias revictimizadoras para la gente. Por eso, hay que afirmarlo categóricamente: cuando se hace sin un marco de integralidad, no es una acción realmente reparadora.

Además de todo lo anterior, tampoco se tuvo en cuenta la realidad psicosocial de la gente, los sentidos y valores que se le podian dar a ese dinero, la realidad de una lógica de consumo que ofrece estatus social y un lugar de reconocimiento, entre otras cosas, que a su vez se convirtieron en factores que generaron que los procesos de indemnización en una parte de la población se convirtieran en un potencial de daño, tal como se ha enunciado desde el comienzo:

Cuando hubo reparación, ahí mismo llegó todo el mundo con los celulares, las motos. Ese es un problema de San Carlos, aquí somos muy amigables con esas cosas que llegan (GF5). La plata se la gastan en maquinitas, en aguardiente, en las primas, en cosas como esas, eso es también falta de consciencia y falta de que la gente no tiene personalidad y falta autoridad con ellos mismos y eso si no lo hace creer uno a nadie porque cada quien es una persona muy distinta y es un mundo muy distinto... (GF6)

Puede plantearse una pregunta al respecto: ¿Qué significa para un municipio como San Carlos, que en un fin de semana de reparaciones se le entregue a la población víctima una cantidad de dinero que puede superar el presupuesto municipal de todo el año? Frente a esto han surgido posturas de preocupación y análisis que hablan de una "burbuja" o de una "bonanza" de las víctimas. Y en términos de la reconstrucción social y económica se preguntan: ¿Qué va a pasar con el municipio cuando pase esta "bonanza"? ¿Qué va a suceder cuando se acabe la plata de las víctimas?

...en una de esas entregas el dato que tengo es que el volumen de esas entregas superó el presupuesto anual ordinario del municipio... significa que la plata que tiene el municipio para hacer acciones públicas está entregada a un número de familias que también hacen inversiones y claro eso también hace un jalonamiento de ciertos sectores de la economía local, pero son presupuestos planeados de una forma diferente a como se haria desde el sector oficial y eso introduce una experiencia de burbuja, es gran cantidad de dinero, 
miles de millones flotando y produciendo una sensación colectiva... Gastados en bienes de consumo, su mayoria, y creo que es como una herencia que se reparte de diferentes maneras en las familias, "a usted le toca esto y ya cumplimos". O sea, cuál es el sentido de esas reparaciones, cómo hacer un seguimiento e intentar entender que significa... (EI3).

Se pueden introducir con este tipo de lógicas, variables potenciales de daño en los marcos culturales y en las relaciones sociales que son complejas de controlar y de mitigar, tal como ya se evidenció en el tema de las relaciones familiares, si previamente no se ha construido ese proceso de reparación desde los mismos proyectos de vida de las personas y de las comunidades. Se introducen falsas diferencias sociales marcadas por la obtención fácil de bienes de consumo, mientras la realidad de la estructura económica de la gente se mantiene:

En las veredas, por ejemplo, donde se estaban dando estas ayudas en ese sentido, me da mucha risa porque llegan a la escuela, en reuniones que ha tenido la junta o asi, llegan esos muchachos con tenis de doscientos y pico mil, unos celulares, por Dios. Entonces, me da mucha risa porque me decía uno de ellos, que llevó un blackberry todo lujoso, unos tenis y yo, uy mi amor, y me dice: Profesora ¿a usted no le da pena con ese celular, usted ganando plata? Y yo: es que yo gano plata, pero la plata que yo me gano, la necesito para vivir bien. Entonces ellos llegan con esas cadenas de oro.... Ellos son esperando a que llegue la plata, que me regalen la Tablet, para pisar la moto, pa' sí. (GF7)

Y finalmente, al poco tiempo, la gente descubre que su situación es similar. Ni hubo reparación, ni hubo superación de condiciones de vulnerabilidad, ni se dio un paso hacia un empoderamiento social. Se trató de un "dinero" que no logró vincularse a un proceso social más completo y complejo, de una dádiva, de un subsidio, además sin significaciones claras en el psiquismo de las personas, con lo cual, pareciera que muchas personas vuelven a ese lugar de vulnerabilidad:

...lo otro es que la gente acabó con la plata muy fácil y están viviendo otra vez la misma situación, porque para ellos 15 o 17 millones de pesos, creyeron que eso no tendría fin, entonces ahora la gente está en iguales o tal vez peores condiciones y porque ya están perdiendo la esperanza de volver a recibir algo. ...no, yo digo que el hecho de que la gente haya recogido el dinero, como la señora dice, aquél que lo invirtió en el ganadito, en las cositas, bienvenido, pero las personas que no supieron hacer las cosas están en peores condiciones... (EG4).

No tenemos un cálculo. No podría decirse cuántas personas optaron por esta vía, cuántas optaron por realizar inversiones que les permitieran proyectar su futuro o mejorar sus condiciones de vida; cuántas lograron sentirse reparadas o cuántas consideraron que se trataba de un dinero "maldito" que "quemaba" las manos y por eso se malgastó. Tampoco cuántas suplieron necesidades básicas en salud y en educación, en vivienda y en otros temas acumulados desde el pasado o intentando tener mejores condiciones para el futuro, que también las hubo en una buena proporción,

...pero hay quienes hacen muy bueno uso, porque yo no creo, no veo, la capacidad de un gobierno ni local, ni departamental, ni nacional de meter a todos en una misma casilla, porque eso depende de la cultura del tener y del haber, hay quienes cogen un pesito y lo 
vuelven dos y hay quienes cogen uno y se gastan diez, es un tema muy de cultura y se ha hecho dentro de los PAARI, todo el acompañamiento para que la gente entienda, estos diez pesos que te llegan ahora serán los últimos por esta línea, úsalos, multiplícalos... Pero no es fácil generalizar, ahí no se puede establecer una línea o una regla de uno a diez... (EI1). ...Yo he escuchado que si hay personas que tienen una actitud diferente frente a la inversión de esos dineros, unos dicen, esto es como sembrarlo, tienen un sentido ritual, algunos si lo emplean, o sea, aqui está representado mi familiar y tiene nombre incluso, está ahí... (EI3)

Lo cierto es que en las conversaciones grupales, en las entrevistas, en los grupos focales estos significados emergentes fueron muy fuertes, claros y evidentes. Y es necesario condensarlos en este texto. No fueron suficientes los talleres de una, dos o tres horas, ni los previos avisos en el trabajo de la administración municipal, porque en gran medida el proceso de acompañamiento necesario para recibir un dinero que tiene significados muy complejos se hizo en muy baja escala y no en la dinámica que se requiere: desde abajo, procesual y con un sentido de reconstrucción del proyecto de vida.

Yo le digo algo antes de eso y es que aqui habemos un grupo de lideres y estamos visualizando diferentes problemáticas y hay aspectos, dentro de los programas, positivos y nosotros notamos. El caso es, por eso quién sabría decir ¿cuántos se jugaron la plata en maquinitas? ¿Cuántos compraron moto? ¿Cuántos hicieron una inversión y perdieron el dinero? ¿Cuántos la invirtieron bien invertida? No lo sabemos, podemos decir de que existen todas esas variabilidades de problemáticas pero que no sabemos en qué proporción y las hay muchas más... A muchos les dieron una hora de charlas, tratando de concientizarlos de que hicieran buena inversión ¿ipero en qué momento se sentaron a realizar un análisis del mercado, para saber qué hace falta y en qué debo invertir? hacer un plan de negocios, que debió haberse hecho. Por ejemplo aqui en San Carlos, en el casco urbano creo que habia ideas de negocios, casi 2 o 3 por cuadra, en una cuadra habia una tienda y el señor ve eso y montan entonces 2 o 3 más. Entonces el tema es que una cosa es invertir la plata $y$ otra es saberla invertir (GF6).

La realidad es la siguiente: de acuerdo a lo presentado al comienzo, prácticamente la totalidad de los habitantes del municipio de San Carlos ha sido afectada directamente por el conflicto armado, puede considerarse víctima. Pero el enfoque de la reparación ha tenido hasta ahora un enfoque individual. Se da una superposición del discurso que tiene que ver con la forma como el derecho, en el marco de un estado liberal, concibe como sujeto de protección y de garantía al individuo. Es decir, los derechos humanos y la reparación se le garantizan a un sujeto individual. El derecho positivo es individualista, tanto en la determinación de responsabilidades y deberes, como en la garantía y protección de derechos. Lo que compele a valorar el daño en términos individuales en una lógica de racionalidad instrumental.

Por tanto, desde este marco, es evidente que a la persona le violaron un derecho, por lo tanto tiene derecho a que le hagan justicia o le hagan reparación, tiene derecho a que le den una indemnización, si no se le restituyen lo perdido, porque si le quitaron algo o si perdió algo, pues tiene derecho a eso, pero no sabemos si nos estamos dando cuenta que se refuerza una lógica de la individualización del daño. No se ve al sujeto integral, al sujeto 
colectivo: un sujeto que se mueve en el territorio de lo público, de lo social, de lo comunitario, sin lo cual no lo puedo comprender; de alli que es fundamental hacer un trabajo o un acompañamiento para restituir esa subjetividad política, puesto que intentar hacerlo como se viene haciendo desde la lógica tecnocrática y burocrática del Estado, o como muchas instituciones de buena voluntad lo están haciendo, desde el compadecimiento de la víctima, que es legítimo y necesario, pero insuficiente, si se hace desde este lugar asistencial, se está corriendo seriamente el riesgo de mantener a este sujeto "despolitizado", sin hacerse cargo de lo público y ocupado en la solución de sus necesidades individuales:

La problemática de la gente de no invertir bien invertido es porque la mayoria de la gente no tiene tierra, entonces yo pago arriendo y trabajo aqui, entonces mejor compran una moto. Lo hacen es por la necesidad que tiene, no por botar la plata. Entonces la mayoría de la gente no tiene en que invertir la plata, no tiene digamos una tierra para trabajar entonces la van gastando en una cosa en la otra, una moto y eso es lo que pasa, la mayoría de la gente no tiene tierra. (GF6)

Si bien, como se ha visto, desde 2013 se está trabajando en un proyecto de reparación colectiva para el municipio, este proceso aún no ha sido apropiado por la población, no lo siente como una acción reparadora y se significa más como una deuda social que el Estado tiene con el municipio desde hace décadas: se trata de centrar la reparación colectiva en la pavimentación de la carretera, por lo menos, en los significados construido por los y las participantes. Es importante este punto, porque si se pone atención a la discusión que se trae, esta estrategia y acción reparadora se ubicaría en el mismo plano de la indemnización económica, es decir: el daño se "arregla" con dinero, con viene materiales, con dádivas. Y sin embargo, nada más lejano y contrario a un proceso de reparación integral; por esta razón van quedando imaginarios y significaciones como los de estos dos relatos:

El Estado no sabe dónde está parado, se sabe que tiene que reparar más de un millón de víctimas, san Carlos la tomaron como modelo, pero no ha habido una respuesta concreta. A unos llega la ayuda humanitaria más rápido, a otros se les demora. El Estado está equivocado. No ha habido capacitación. La atención es muy lenta. Siendo el modelo de reparación para el país. (GF2) Yo digo en dos palabras, la reparación ha sido apresurada e inequitativa (GF10)

Además de todo lo anterior, y como parte de eso que no se logra ver en la relación que el Estado ha establecido con esta población, dentro de los grupos de discusión y las entrevistas individuales nos encontramos con un gran número de personas, familias o colectivos que no han sido reparados y que no han recibido prácticamente ningún tipo de ayuda humanitaria. A la larga, esta situación, también recogida en 2011 por la investigación de la CMH, y que al parecer aún no ha sido subsanada, trae consigo procesos de división comunitaria, pugnas y luchas entre vecinos o miembros de organizaciones para alcanzar algún tipo de "ayuda", y nuevamente se convierte en un factor que no favorece la reparación integral, sino que genera tensión y riesgo de nuevas rupturas en el tejido social,

Eso es lo que yo digo, porque mi mamá nunca se desplazó, a pesar de todas las situaciones y mi mamá ha tratado de ser incluida o alguna cosa y no, mi familia no, muchas personas que uno conoce y que de pronto no se atreven a hablar no... Acá hay mucha gente del 
municipio que no ha sido asistida de ninguna manera, ni reconocida como víctima del conflicto, ni ha tenido asistencia de ninguna clase (GF9).

Es decir, un proceso de reparación colectiva, que debería atender a este tipo de situaciones y problemáticas y ocuparse de la reconstrucción del tejido social, como una forma de matizar algunos efectos negativos de la reparación individual en términos de divisiones, separaciones y rupturas, se plantea en el mismo plano, atiende a una deuda social del Estado central; y se olvida de cientos de personas que aun estando por fuera del registro de víctimas, hacen parte de la historia del municipio y padecieron la más cruda violencia en su experiencia cotidiana. Y que sin embargo, en la lógica descrita, se sienten incluso excluidas y experimentando una forma de discriminación, lo que ahonda fracturas en la vida de la comunidad:

Que se nos acepte como víctimas, una de las partes y la otra que estemos en igualdad de condiciones, que el Estado nos acepte y que entienda que también tenemos derechos, que también tenemos necesidades, que también necesitamos reparación en todos los aspectos, no solamente económica, también se necesita reparación psicosocial, son muchas cosas (GF9)

Todo lo anterior ha generado en la población, según las voces de los y las participantes en esta investigación, una sensación de desprotección y de desesperanza. No se ve claramente el norte del proceso, no se identifican las rutas. La gente asiste pasivamente a las consultas, a la ejecución de los proyectos, unos reciben "ayudas", indemnizaciones, proyectos, otros sólo algunas de estas cosas, otros nada; pero no hay claridad, no se despeja un horizonte, no se perciben los caminos. Es como si no se diera planeación, como si no se lograr aterrizar las múltiples propuestas en el territorio:

Yo pienso que el Estado ha tratado de reparar, pero está experimentando; no ha habido una planeación seria, no están en contexto, no hay articulación ni coherencia en sus planes, en la ejecución, están experimentando a ver qué da resultado y no veo muy lógica la manera de hacer reparación. No hay algo sostenible, nada seguro y viendo que el municipio, las condiciones vienen de un proceso de retorno, no hay dinámica económica. No hay planeación ni en lo agropecuario, no se ha mirado el plan agropecuario municipal, al CMR, que son cosas que deberian funcionar desde hace mucho tiempo. En estos momentos es un experimento. Las primeras personas no se les da algo más sólido, más estable, no tienen alternativas. La reparación de las primeras víctimas está en eso, no hay seguimiento articulado... (GF3)

\section{Los problemas de la no-articulación institucional y la fragmentación en la reparación.}

Uno de los problemas fundamentales que se siguen observando en el proceso de reparación es: "la poca coordinación y corresponsabilidad entre las diversas entidades territoriales, la falta de continuidad en los programas y de enfoques integrales de atención" (CMH, 2011, p. 362). Algo que se reportaba en el PIU de 2006, en el informe de la CMH en el 2011 y en este proceso investigativo en el 2014/2015. Por eso, este participante, cercano a la administración municipal de San Carlos, expresa que después de varios años, una de las 
principales acciones que se pueden desarrollar en el municipio es la de la articulación institucional de la reparación con una lógica territorial:

No, yo creo que es integrar las ofertas, integrar las ofertas, que el estado no ande como rueda suelta este proyecto por alli, este proyecto por alli, integrar las ofertas y respetar mucho los planes de desarrollo local (EI1).

Los sancarlitanos participantes en este proceso de investigación piensan que su municipio es un lugar de experimentación, de ensayo y error, donde el Estado ha puesto a prueba varios programas y proyectos, por lo tanto, sienten en buena medida, que además de no estar siendo reparados, están siendo usados como "conejillos de indias" para poder construir una política pública de reparación que, aun así, sigue sin dialogar con las realidad de los habitantes del territorio:

Hoy nos confirma a nosotros que lo de la reparación colectiva y la indemnización apenas experimentan con nosotros, con base en esto, obvio que investigan en base de datos $y$ miran el rubro de desplazados en San Carlos y se dice que ya estamos: el pueblo piloto en reparación y ¿cuántos desplazados? 19.000 y la indemnización no va en 1.500 si quiera. Entonces mire (GF4).

De alli que se perciba una incoherencia en todos los órdenes: entre lo que se promete y lo que no se cumple, en la descoordinación de las diferentes instituciones, en que se han entregado miles de millones de pesos en acciones de reparación, de retorno y ayuda humanitaria, pero que hay una buena parte de la población que no hace parte de estos procesos:

Le puedo decir a usted que en el municipio piloto del país hay hambre. Sí. Por eso se lo digo, se lo digo, porque a mí me ha tocado ver tanta gente, cómo se han reparado unas cuantas, yo diria sinceramente que acá en San Carlos reparadas o medio reparadas un 10\%, mejor dicho, asistidas. (EG2) Este pueblo es dizque piloto, el que quiera venir a investigar llega, el que quiera medir cosas sobre victimas viene aqui. Incluso es premio nacional de paz, pero falta voluntad para organizar a las personas (GF5).

La situación se torna más compleja cuando el discurso oficial habla de unas metas cumplidas, unos procesos cerrados y unas acciones desarrolladas que darian cuenta del cumplimiento con la población. Esto en algunos casos puede generar indignación y en otros, preguntas y cuestionamientos profundos frente a las instituciones; puesto que se cree que están ciegas a la realidad de la gente, o que la voluntad de reparar está sólo en el discurso y no en las acciones concretas. Lo cual puede ser leído como burla o como incumplimiento:

...pero aqui en San Carlos en este momento decir, o atreverse a decir la misma alcaldesa que aqui en San Carlos, el pueblo como lo ha dicho en la prensa, está siendo reparado casi en su totalidad, me parece que es una incoherencia, ella atreverse a... cualquier persona que pertenece a una institución, es un incoherencia decir que está casi resuelto en su totalidad (EG1).

Así pues, la gente siente que la reparación está lejana aún, y aun cuando las instituciones (UARIV, Alcaldía, entre otras) afirmen que se trata de un proceso gradual en el marco 
de cumplimiento que proporciona la ley 1448, y que se llegará a toda la población, el malestar que se ha generado es también responsabilidad de las formas como se ha llevado el proceso y las inconsistencias que se han tenido: bases de datos que no se cruzan, sobre-intervención en algunas comunidades y cero atención en otras, falta de articulación institucional y otros problemas organizacionales que hacen ver incoherente al discurso institucional de la reparación y muestran su inconsistencia, con lo que trae consigo de pérdida de la credibilidad.

Aventurando una reflexión, podría decirse que uno de los problemas fundamentales, si se acepta que existe la voluntad politica para realizar la reparación integral, está situado en lo que podríamos denominar: la lógica burocrática del Estado, los tiempos de contratación, los tiempos de revisión, el paso por varios funcionarios de cualquier dispositivo que hacen que cada propuesta, cada acción deba ser revisada y reprocesada por diversas instancias que no permiten continuidad en los proyectos y en las acciones. Este problema más que responder a una situación tecnocrática, que será abordada más adelante, responde al orden burocrático y al ordenamiento jurídico que no es posibilitador de acciones transformadoras, especialmente, desde el Estado.

...de pronto ahora con algunos esfuerzos, intenciones que se tienen, pero no, es eso el modelo de intervención, aunque uno también entiende que es la primera vez que en Colombia se hace esto, entonces el gobierno tampoco tiene la experiencia como para abordar un proceso de reparación, entonces me imagino que ellos empezaron, fueron mirando errores que han venido corrigiendo y uno realmente ve que hay puntos que antes no se pensaban y que ahora se están pensando, que hace parte del mismo proceso (EI2).

Además de lo anterior, en términos de la reparación, el problema tiene que ver con la forma como está constituida la ley 1448 de 2011 (ley de víctimas), que, si bien retoma el marco jurídico internacional y la normativa sobre el derecho a la reparación integral, asume las dimensiones de la reparación como compartimentos separados, desde una perspectiva temática y jurídica, y no desde una mirada territorial e integral, que considera que el sujeto de la reparación, individual y colectiva, no puede dividirse por pedazos o atendidas estas dimensiones por diversos agentes, cuando en la vida real y cotidiana, todos estos aspectos se viven integradamente. Por tanto, se comete un error fundamental: se quiere aplicar un ordenamiento jurídico e institucional a la realidad y se deja de ver la misma experiencia cotidiana y el mundo de la vida de la gente, de tal manera que se intenta forzar esta experiencia para que encuadre dentro del marco institucional, y no a la inversa (Cfr. Bello \& Millán, 2007). Desde allí se tiene garantizada una acción que tendrá muchas dificultades para ser transformadora.

Desde este marco normativo, también puede observarse que el trabajo psicosocial es concebido como un compartimento ubicado en el campo de la salud, con unas acciones específicas; y podría ser válido que se ponga alli, en términos administrativos; pero luego, por ejemplo, la memoria la ubicamos en un plano más social, más antropológico, más histórico. Pero como hemos visto, termina o bien solapado e invisibilizado dentro de un marco de salud mental o un modelo médico, o rescatado como metodologias de trabajo colectivo que muy poco aportan a procesos de transformación más profundos si se desarrollan como actividades superpuestas sin un marco, sin una mirada y una perspectiva. 
Por tanto, empieza a suceder lo que ha pasado hasta ahora: se constituyen varias instituciones, equipos burocráticos, equipos en terreno que, cada vez más, al irse fortaleciendo como entidades, como instituciones autónomas se van separando entre sí y van teniendo, con frecuencia, dificultades para el diálogo: por los tiempos, por las dinámicas de los proyectos, porque tienen que responder a unos indicadores, a unos resultados. Resulta, entonces en la práctica, que terminan en una misma comunidad varios equipos, que deben abordar, intervenir, atender a los mismos sujetos; unos equipos haciendo memoria, otros equipos haciendo trabajo psicosocial, otros dando indemnizaciones, otros haciendo restitución de tierras: “...viendo a la gente enchalecada, de azul, de rojo, pero no más, porque mire ella que trabaja en el programa y vienen a guerrearle el programa, si usted va a la alcaldía y ve ese viaje de gente de azul, pero no más, trabajan, luchan y todo eso" (EG2).

Esta reflexión se mantiene en la línea de lo expresado en la investigación de la CMH: “... además de la descoordinación y la sobreoferta, en la mayoría de los casos, no hay continuidad, lo que la convierte en una acción que poco ayuda a las persona y que adicionalmente, aumenta el riesgo de revictimización" (p. 368). Esto que se dice de la atención psicosocial, es válido para la mayoría de proyectos y acciones que se han desarrollado en el marco del retorno (desde 2007) y los posteriores ejercicios de reparación en el marco de la ley 1448 de 2011. Así pues, la gente en San Carlos, ve con buenos ojos la acción que el Estado viene desarrollando en el proceso de reconstrucción del tejido social, la valora, cree que es necesaria, la ha pedido y espera que continúe, pero al mismo tiempo identifica que hay problemas serios en el hecho de ser un lugar de experimentación y en las dificultades que el mismo sistema de organización del Estado genera en la reconstrucción del tejido social cuando pretende meter sus realidades dentro de marcos epistémicos, metodológicos e institucionales tan restringidos. De allí un reclamo para que se puedan realizar acciones más participativas e inclusivas:

Bueno yo creo que lo valioso de esto es que ha permitido un reconocimiento, una oferta y ha permitido que a San Carlos lleguen programas, organizaciones que en ningún lugar de Colombia han llegado y eso indudablemente ha favorecido muchos procesos acá. Igual sombras de estas claro una preocupación muy grande, porque cuando usted es un piloto ensaya, se hacen cosas buenas, pero también se cometen muchos errores, que luego son perfeccionados en otros municipios, entonces esa si es como la dificultad porque de alguna manera al ser este como el laboratorio para tantos temas, cometen muchos errores, pero ahi está lo valioso de ser un piloto que finalmente es ser un municipio que ayuda a construir y enseñar (EI2).

\section{Sobre la restitución.}

En torno al tema de restitución de tierras es importante plantear cuál es el horizonte de la discusión. Como derecho, en el marco de la normativa internacional, implica que se puedan garantizar condiciones iguales o mejores a las víctimas en relación con las pérdidas que se han sufrido. En el marco de la ley 1448 se ha limitado al ámbito de la restitución de tierras, puesto que por las características de nuestro conflicto armado, es quizás el tema más sensible como política de reparación. En una investigación de la Fundación Social, Marín \& Gaviria (2010), planteaban que en un conflicto en el que una inmensa mayoría de la población víctima han sido expulsados de la tierra y el despojo de la misma ha estado a la base de las 
dimensiones estructurales del conflicto mismo, las víctimas atribuyen un peso significativo a la restitución, puesto que se han perdido tierras, bienes materiales, animales, casas, cosechas y muchos otros recursos económicos que le permitian a las familias sobrevivir. También consideraban que para esta población la compensación era una medida fundamental (siempre y cuando implique un ejercicio equitativo frente a lo perdido), puesto que significa el cubrimiento de necesidades económicas, ya que fueron éstas necesidades las que más se han visto insatisfechas por esa gran cantidad de personas desplazadas y despojadas (5.5 millones). De igual manera sucede en San Carlos, donde los y las participantes en esta investigación le atribuyen a la restitución un valor fundamental, mucho más cuando en la práctica se han encontrado con ejercicios de retornos con apoyos o sin ellos y de reparación centrada en la indemnización que no han logrado compensar lo perdido.

Para los y las participantes, es mucho más significativo que se pueda dar una restitución de los bienes y de la tierra, que una indemnización, porque la restitución implica una superación de condiciones de vulnerabilidad, posibilidades de desarrollar con su propio trabajo, condiciones mejores de vida. Mientras que con el dinero de la indemnización o con las "ayudas", siempre se estará en un lugar de dependencia frente al Estado. Así pues, la restitución está en un orden más claro de reparación integral, que la compensación. Es más, desde la perspectiva normativa, esta segunda medida, se ejecuta, en el caso de no poder cumplir la primera, es decir, intentando "compensar" con algo lo perdido:

Con esa plata, si es verdad que eso es pa uno, con $\$ 30.000 .000$ le deberían comprar a uno una tierra bien buena, teniendo donde trabajar la casa la va parando. No tiene uno trabajo, hay trabajo, la pesca, la cacería, todo eso, trabaja. De que sirven casas en Medellín, San Carlos, de nada, porque ¿qué hace uno por allá?, nada, ver televisión, los niños coger la calle, ¿qué come uno?, en cambio uno en la tierra no hay trabajo pero siembra comida, trae un pescado, un animal, cualquier cosa (GF12).

Este punto muestra un elemento fundamental que habla de la dignidad de la gente y de la importancia de construir una mirada de reparación que permita reconstruir realmente los proyectos de vida de las personas, las familias y las comunidades. Para ello será siempre necesario contar con ellos y ellas, más que ejecutar programas y proyectos donde más allá de la consulta, no se toman en cuenta los aspectos de sentido vital, social y cultural de la gente, sus modos de vida, sus economías domésticas, sus relaciones cotidianas, su mundo de la vida, sus sentidos, símbolos y significados:

A que nos referimos, eh, es como el restablecimiento de cierta forma, porque una reparación cómo se maneja el tema de reparación integral... (EG2). En vez de comenzar al derecho empiezan los procesos al revés, yo como víctima del conflicto armado realmente cuando me hablan de reparación integral yo le digo: "entrégueme los 4, siquiera los 3 o 4 componentes esenciales que yo necesito para resolver adecuadamente y decirle al Estado que no necesito más de usted" (EG1).

Aun así, no logramos recoger a fondo los significados de la gente sobre la restitución, ni se tuvieron claridades sobre este proceso y sus implicaciones para los y las participantes, porque no tiene el nivel de desarrollo e implicación en el marco del municipio, por lo menos no en relación con las demás acciones que abordaron con mayor profundidad los y las 
participantes. Además hay preguntas profundas: ¿Para qué restitución si hay territorios que están en nuevas disputas por los megaproyectos o si no hay condiciones de seguridad para recibirla? Esto hace referencia a la aprobación de la licencia ambiental del proyecto Porvenir II que implicará nuevos desplazamientos a población que es retornante en el municipio. Sin embargo este punto se profundizará más en el capítulo sobre garantías de no repetición.

...restitución de tierras y fuimos piloto en eso sin embargo algunas tierras en proceso de restitución, las van a inundar o a destinar a proyectos mineros y cosas por el estilo, le restituyo la tierra y luego vengo con otro proyecto minero o energético y se la quitan, lo acabo de joder, si es que de pronto doy una compensación por él (GF3).

El tema de la restitución, en el derecho internacional, hacer referencia a intentar que las personas víctimas puedan regresar, por lo menos, a su situación anterior, en términos de calidad de vida, bienes y oportunidades. Sin embargo, en muchos casos, en el municipio de San Carlos, esto no ha sido posible ni se ha podido desarrollar. Como se ha dicho, las medidas de la UARIV se han centrado en el tema de la indemnización, pero como el tema de restitución, centrado en la tierra está en otra institución, se plantean dinámicas, procesos y destinatarios, que en muchos casos, son diferentes, sin que se puedan ver con claridad los vasos comunicantes de estas acciones en el territorio. De allí que haya confusiones, generadas también porque algunas personas "gozan" de unas condiciones de atención por varias de estas instituciones y otras, en muchos casos, ni siquiera han podido disfrutar de lo prometido:

El decir era que las fincas nos las iban a entregar como las teniamos y ahí se están cayendo y a ver, quién responde por eso. Yo me vine retornada de Medellín con esa ilusión y la finca se está cayendo todavía. Hay mucha gente que recibe, tienen edificios y casas en Medellín y todo, piden y siguen dándoles. Yo también perdí todo allá y vea, ¿qué? Callada, mejor uno no hablar (GF4).

Lo cierto es que una de las medidas sobre las que hay más desconfianza y no se tienen muchas esperanzas es la de restitución de tierras. Es conocido en el país los conflictos que se vienen presentando en Córdoba, Urabá y otras regiones en disputas por esas tierras entre reclamantes y los nuevos "propietarios" de las mismas (Verdad Abierta.com, 2014); lo que ha evidenciado la incapacidad del Estado para determinar la magnitud de los hechos acaecidos en torno al conflicto armado, especialmente en relación con el tamaño, las complejidades y confusiones en torno al despojo de la tierra:

Yo estoy metido en el tema de restitución, si quieren propiamente van y miran la propiedad mía aqui en el puente; primero, San Carlos no tiene garantias, segundo, están en varios programas de hidroeléctricas, tercero, uno habla de restitución y que está en espera, está en espera y uno va a la oficina de restitución y en la mirada del cliente que lo atiende le muestra la impunidad, aqui se dice que se restituye $y$ se restituye y uno no ve que han restituido (EG1).

El más complejo y que se presenta en otras regiones tiene que ver con la "venta" de las tierras en los contextos del conflicto. En términos de la ley, las ventas realizadas en un contexto de amenaza, destrucción y violencia no tendrían validez; puesto que quienes compraron en 
estas circunstancias lo habrian hecho no de buena fe. Por lo tanto, el propietario inicial tendría derecho a la reclamación:

Si han venido pero eso tiene unos requisitos, por ejemplo, yo regalé la tierra eso no es vender, ya uno tiene que ser despojado de la tierra por paramilitares, pero uno diciendo la verdad, que la vendió para sobrevivir en el pueblo, me toco venirme, mataron al hermano mio, a un tío y como le dice uno eso, si le dicen que usted la vendió, que no se la quitaron y no hay reparación para eso (GF12)

Porque las personas saben que entrar en este conflicto puede implicar problemas para su seguridad, para su vida y la de su familia, "aparentemente es una situación de normalidad, pero es una anormalidad. Eso es un tema que hay que ponerlo en discusión, aqui es lo que pasó, pero se debe poner en el debate con la ley" (GF, 12).

\section{Conclusiones.}

Es necesario ahondar en investigaciones de tipo regional y nacional en torno a esta problemática sobre todo en el marco de un avanzado proceso de Negociación que a la fecha noviembre de 2015, se viene realizando con resultados importantes, entre la insurgencia de las FARC-EP y el gobiernos nacional, negociación en la que uno de los ejes centrales ha sido en el tema de Victimas, por lo que urgen estudios que visibilicen los necesarios ajustes a la implementación ya sea de una nueva ley o un Sistema modificado que asuma los aprendizajes que se han logrado a la fecha en el tema.

Y esto es bien importante máxime en un contexto como el colombiano, en el que la mayor parte de la población víctima tiene insatisfechas sus necesidades básicas, en el que el Estado debe trazarse el complicado, pero necesario reto de trascender la reparación material, limitada a una indemnización no compensadora, que cuando, además, llega sin ninguna otra medida que la complemente, puede significar para las personas víctimas un paño de agua tibia o sólo una ayuda, que realmente no aporta a su proceso de recuperación ni a la reconstrucción del tejido social.

Si bien, para las personas víctimas de diferentes naciones, incluida Colombia, la reparación material suele ser considerada como la más importante, lo que puede hallar fundamento en las condiciones de vulnerabilidad en las que estas generalmente se encuentran, en sus múltiples necesidades básicas insatisfechas y en las condiciones estructurales que obstaculizan la transición, la forma en que las indemnizaciones se están llevado a cabo han impactado negativamente en la identidad, formas de relación, escalas morales de las personas víctimas, generando procesos sociales y culturales que rompen con formas tradicionales de relación y con dinámicas, incluso económicas, que afectan la vida cotidiana del municipio y sus comunidades.

Acompañar estas acciones de la dimensión simbólica y el acompañamiento psicosocial, será siempre una labor compleja si se quiere partir de la vida, los significados y los contextos de la gente; puesto que requiere una transformación de la misma estructuración operativa del Estado. Además de lo anterior, en un contexto como el de San Carlos, con tierras codiciadas para diversos proyectos de desarrollo o explotación minera y de recursos naturales, son 
fundamentales medidas claras de no repetición que protejan el territorio y los proyectos de vida de sus habitantes. Pero además, verdaderas políticas con justicia social que permitan transformar su situación de exclusión y empobrecimiento históricos.

Al igual que el informe de la Mesa Nacional de Victimas de organizaciones Sociales, se ha ce un llamado a repensar los tiempos que establece la Ley 1448, en tanto que a la fecha, Junio de 2015, la reparación integral no ha sido tal, haciéndose necesario re-pensar y modificar el plazo de 6 años que aún faltan, según la Ley 1448, para dar por concluido el proceso de reparación, esto en tanto, no son suficientes para lograr una reparación integral real, del total de víctimas incluidas en el Registro Único de Víctimas (Ruv).

Urge encontrar rutas que agilicen las dinámicas burocráticas en las que se hace llegar "las ayudas", esto en tanto las instituciones, al irse fortaleciendo como entidades que ejecutan dineros públicos o de cooperación internacional se van separando entre sí y van teniendo, con frecuencia, dificultades para el diálogo: por los tiempos, por las dinámicas de los proyectos, porque tienen que responder a unos indicadores, a unos resultados lo que en la práctica termina es desorientando a la comunidad generan altas expectativas que el últimas no se cumplen. Estas lógicas deja insatisfacción en ambos lados: las personas que laboran en las instituciones porque piensan que sus esfuerzos y acciones no están siendo reconocidos por la población, pero que no logran ver que la forma como han estructurado la relación con la población implica verticalidad, paternalismo y ponerse en el marco de una relación "caritativa", lo que en el contexto de violaciones de derechos y ejercicio de la reparación integral, los deja siempre en deuda.

Existe desconfianza y no se tienen muchas esperanzas en la de restitución de tierras.

En este punto es muy importante revistar el concepto de utilidad pública de cara a la implementación de la Ley 1448 en tanto muchas de las zonas a las que han retornada las personas que fueron desplazadas por la violencia armada, ahora ven llegar los Mega-proyectos Mineros y Energéticos, avalados por el Estado, proyectos que se imponen de tajo, y que piden la expropiación por vía administrativa, generando desesperanza, desazón, incertidumbre ante una nueva ola de desplazamiento ahora, por vía de la ley y el llamado Desarrollo.

Se presentan varias dificultades en la implementación de algunos proyectos productivos, puesto que se mantuvo una relación vertical que no posibilitó algunas transformaciones que tuviesen en cuenta las reales construcciones y necesidades de la población.

Es de identificar y reconocer que la gran mayoría de los habitantes del municipio han retornado por cuenta propia; en muchas ocasiones en situaciones muy complejas y con dificultades enormes

Aun así, se pudo evidenciar varios proyectos y ejercicios de retorno altamente significativos que evidencian algunos aciertos que demuestran que desde el Estado, cuando hay voluntad política, puede desarrollar acciones con mejores pronósticos y posibilidades.

Un elemento fundamental que para la población puede dar cuenta de la real efectividad de los procesos de reparación, de retorno y restitución es en los que la dignidad de la gente se 
vea recuperada gracias a que se permita reconstruir realmente los proyectos de vida de las personas, las familias y las comunidades diferente a la imposición de proyectos externos e impuestos con tiempos y dineros determinados.

\section{Referencias Bibliográficas.}

Balvín Alvarez, J. B., Insuasty Rodriguez, A., Bastidas, W., Carrion, J., \& Pineda, J. E. (2010). Victimas en contexto de violencia e mpunidad. Medellín. Medellín: Instituto Popular de Capacitación (IPC).

Barkan, E. (2000). The Guilt of Nations. New York : Norton.

Baró , M. (1990). Guerra y Salud Mental. En Psicología social de la guerra. San Salvador: UCA editores.

Baró, M. (1989). Sistema, grupo y poder. Psicología social desde Centroamérica II. San Salvador: UCA editores.

Beristain, C. (1999). Reconstruir el tejido social. Barcelona: ICAIRA.

Beristain, C. (2008). "Memoria colectiva y reconstrucción de sociedades fracturadas por la violencia". En "Verdad, memoria y reconstrucción: Estudios de caso y análisis comparado”. Bogotá: Centro Internacional de Justicia Transicional ICTJ.

Beristain, C. (2009). Diálogos sobre la reparación: que reparar en los casos de violaciones de derechos humanos. Quito: Ministerio de Justicia y Derechos Humanos.

Beristain, C. (2010). El derecho a la reparación en los conflictos socioambientales. Bilbao: Hegoa y Universidad del país Vasco.

Centro de Memoria Histórica CMH. (2011). San Carlos: Memorias del éxodo de la guerra. Bogotá: Editorial Taurus.

Gómez Isa, F. (2006). El derecho de las víctimas a la reparación por violaciones graves y sistemáticas a los derechos humanos. En F. Gómez Isa, El derecho a la memoria, Giza Eskubideak- Derechos Humanos. Bilbao: Alberdania.

Gónzalez Chavarria, A. (2010). Justicia transicional y reparación a las víctimas en Colombia. Revista Mexicana de Sociología, 72(4), 629-658.

Insuasty Rodriguez, A., Jesús William, B. A., \& Cadavid Acevedo, P. (2009). Victimas, Violencia y despojo. Medellín: Litoimpacto.

Jaramillo , P. (2012). Deuda, desesperación y reparaciones inconclusas en la Guajira, Colombia. Bogotá: Antípoda. 
Jaramillo Marín, J. (2010). Narrando el dolor y luchando contra el olvido en Colombia. Recuperación y trámite institucional de las heridas de la guerra. Revista Sociedad y Economía, 205-228.

Jaramillo Marín, J. (2010). Reflexiones sobre los usos y abuso de la verdad, la justicia y la reparación, en el proceso de justicia y paz colombiano (2005-2010). Ciencia política, 15(1), 13-46.

Mack, H. (2007). Justicia transicional en Guatemala: la confrontación politica y la crisis de gobernabilidad diluyen las opciones de examinar el pasado. En Serie enfrentando el pasado. El legado de la verdad: impacto de la justicia transicional en la construcción de democracia en América Latina. Bogotá: ICTJ.

Marin Ortiz, I., \& Gaviria Betancur, P. (2010). Elementos para una politica de verdad, justicia y reparación integral para las víctimas. Bogotá: Fundación Social.

Mesa Nacional de Victimas conformada por organizaciones sociales. (13 de Junio de 2015). Avances Y Retrocesos: Ley De Víctimas Y Restitución De Tierras. Obtenido de Kavilando.org: http://kavilando.org/index.php/2013-10-13-19-52-10/conflictosocial-y-paz/3650-avances-y-retrocesos-ley-de-victimas-y-restitucion-de-tierras

Olaya, C. (2012). Nunca más contra nadie. Ciclos de violencia en la historia de San Carlos, un pueblo devastado por la guerra. . Medellín: Cuervo Editores.

Olaya, C. (2015). La violencia sociopolítica y sus impactos en el municipio de San Carlos, Oriente de Antioquia. Revista Kavilando, 6(2).

Pécaut, D. (2001). Guerra contra la sociedad. Bogotá: Editorial Planeta Colombia.

Pécaut, D. (2003). Violencia y politica en Colombia. Elementos de reflexión. Medellín: Hombre Nuevo Editores.

Rebolledo, O., \& Rondón , L. (2010). Reflexiones y aproximaciones al trabajo psicosocial con víctimas individuales y colectivas en el marco del proceso de reparación. Revista de Estudios Sociales, 40-50.

Sikkink, K., Marchesi, B., Dixon, P., \& D` Alessandra, F. (24 de Octubre de 2014). Reparaciones integrales en Colombia: logros y desafios. Evaluación comparativa y global. Obtenido de static.iris.net: http://webcache.googleusercontent.com/ search?q=cache:sqz-gxTcPQ4J:static.iris.net.co/semana/upload/documents / Documento_409315_20141116.pdf+\&cd=1\&hl=es-419\&ct=clnk\&gl=co

Unidad de Atención y Reparación Integral a las Víctimas UARIV. (2014). Informe de gestión 2011-2014 en el municipio de San Carlos. Bogotá: Comunicación interna de subdirectora de la entidad. 
Uprimny Yepes, R., \& Guzmán Rodríguez, D. (2010). En búsqueda de un concepto transformador y participativo para las reparaciones en contextos transicionales. Revista Colombiana de Derecho Internacional, 231-286.

Utas, M. (2005). Victimicy, girlfriend, "soldiering: tactic agency in a young woman's social navigation of the Liberian war zone. Antropological Quartely, 78(2), 403-440.

Verdad Abierta. (21 de Diciembre de 2014). Verdad Abierta. Obtenido de verdadabierta. com: http://www.verdadabierta.com/lucha-por-la-tierra/5558-debates-de-larestitucion-de-tierras-en-2014

Viaene, L. (2008). Justicia Transicional y Contexto Cultural en Guatemala: Voces Q`eqchiès sobre el Programa Nacional de Reparaciones. En La vida NO tiene precio: acciones y omisiones del Resarcimiento en Guatemala. Guatemala: Magna Terra Editores.

Villa, J. ( Octubre del 2014). Un análisis crítico a la intervención psicosocial con víctimas del conflicto armado en Colombia. . IX Cátedra Internacional Martín Baró. Bogotá: Universidad Pontificia Javeriana.

Villa, J. (2013). Consecuencias Psicosociales de la participación en escenarios de justicia transicional en un contexto de conflicto, impunidad y no-transición. El Ágora USB, 13(2), 307-338.

Villa, J. (2014). Recordar para reconstruir: El papel de la memoria colectiva en la reconstrucción del tejido social, el empoderamiento colectivo, la recuperación de la dignidad y la transformación subjetiva de las victimas del conflicto armado en tres regiones de Colombia. Medellín: Editorial Bonaventuriana.

Villa, J. D., \& Insuasty Rodriguez, A. (2015). Significados en torno a la reparación, la ayuda humanitaria, la indemnización y la restitución en víctimas del conflicto armado en el municipio de San Carlos. El Agora USB, 15(2), 419-445.

Villa, J., Londoño, D., \& Barrera, D. (2014). Reparación a las víctimas de dictaduras, conflictos armados y violencia política. Parte I. El Ágora USB, 14(2), 339-376.

Villa, J., Londoño, D., \& Barrera, D. (2015). Reparación a las víctimas de distaduras, conflictos armados y violencia politica en sus componentes de compensación, satisfacción, rehabilitación y no repetición. El Ágora USB, 15(1), 217-240.

Yzerbyt, V., \& Demoulin, S. (2010). Intergroup relations. En S. Fiske, D. Gibert, \& G. Lindzey, Handbook of social psychology (5th edition ed., págs. 1024-1083). Hoboken, NJ: Wiley. 